\title{
Investigating Warm and Humid Climate with the Approach of Production of Quantitative and Qualitative Architectural Models
}

\author{
Maryam Bahoush a , Amir Salehabadi a * \\ ${ }^{a}$ Department of Architecture, Central Tehran Branch, Islamic Azad University, Tehran, Iran.
}

Received 03 January 2018; Accepted 17 March 2018

\begin{abstract}
Climate change is one of the most significant threats facing the world today. Buildings are one of the largest energy consuming sectors in the world. Most contemporary buildings are highly dependent on air conditioning systems and electricity, reliant on fossil fuels and increasingly unable to adapt to a warming climate. Iran's hot and cold climatic regions are vast. With the advancement of technology, life in every weather condition is possible. Humans can provide living conditions. Passive design responds to local climate and site conditions in order to maximize the comfort and health of building users while minimizing energy use. The key to designing a passive building is to take best advantage of the local climate. Passive cooling refers to any technologies or design features adopted to reduce the temperature of buildings without the need for power consumption. Today been proven that seasonal fossil contamination causes irreparable damage to our planet's ecosystem, which is the result of global warming. According to studies conducted so far, the use of clean fuel cannot alone meet our needs in severe weather conditions. Eco-friendly architecture helps to save energy by avoiding energy losses. In this paper, with the careful analysis of weather information in Dezful, computer software solutions provide architectural solutions that can be measured and can be applied to each of the suggested patterns as Checked a number. Gaven Comfort conditions in this city without any static and dynamic system is $17.7 \%$ of the year, which can be increased by $78.8 \%$ of the year using static systems.
\end{abstract}

Keywords: Comfort Conditions; Climate; Climate Design; Energy Dissipation; Climate Approach.

\section{Introduction}

Global warming is one of the most critical components of environmental degradation. Global temperature which has risen by over $0.7^{\circ} \mathrm{C}$ in the last 300 years is predicted to rise by up to $8^{\circ} \mathrm{C}$ by 2050 in the worst global warming scenario (IPCC, 2007). The building sector is one of the major energy consumers in the world. The proportion of total energy use attributable to buildings generally ranges from 10 - 15\% in undeveloped countries to more than $40 \%$ in the developed countries.

Recently, the risks of global warming and the depletion of fossil fuels have required reductions in energy consumption in many countries [1]. The building sector is one of the largest economic sectors worldwide; it generally accounts for one-third of the global energy consumption and leads to a significant amount of greenhouse gas emissions [2]. Due to population growth, increased urbanization, and improvements of living standards, most of the energy-consuming buildings will be located in urban centers of the developing world. The depletion of energy resources and the risk of climate change require a sustainable development path based on renewable sources of energy and energy efficiency [3].

In Iran statistics show that buildings account for about 39\% of total energy consumption (IFCO, 2007). According to a report in "The 2nd conference of Fuel Conservation in Buildings" in Tehran (2003), the amount of energy consumed

* Corresponding author: amirsalehabadi7@gmail.com

http://dx.doi.org/10.28991/cej-0309122

> This is an open access article under the CC-BY license (https://creativecommons.org/licenses/by/4.0/).

(C) Authors retain all copyrights. 
in buildings in Iran is equal to 30\% of its annual oil income (equivalent to US\$15 Billion in 2005), with 50\% of this being wasted. Using and wasting energy, air-conditioned energy- dependent buildings result in more emissions of greenhouse gases that drive global warming [4].

Climate has a significant impact on the performance of the building and its energy consumption. Reducing energy consumption, using natural resources and providing comfortable, healthier and sustainable living spaces are the aims of a climatically responsive sustainable building design [5].

Therefore, climate-responsive building design has become a necessity rather than an option for energy conservation and carbon emission reduction [6]. Revisiting traditional buildings with satisfactory climate adaptation is considered necessary for inspiring climate-responsive building designs. Traditional buildings are constructed using locally available resources to address local needs. Their construction techniques and specifications are based on knowledge achieved through trial and error. Because the climate, socio-cultural factors, economy, materials and technology vary among locations, the traditional buildings that compose the built environment are also region-specific. As examples of harmony between people, architecture and nature, traditional buildings are a valuable resource for modern buildings because of their effective and flexible solutions that promote sustainability [7]. Studies and experiences have proven that the vernacular architecture of our ancestors was an appropriate source to study and that solutions should be reused in designing buildings [8].

Vernacular dwellings of Iran have the significant relationship with local climate [9]. Since some of the most important aspects for reaching sustainability and sustainable development in cities are adaptability to climate conditions and reduction of energy consumption, climatic design, which is seen in the vernacular architecture of Dezful, could be a good method for preventing excessive energy consumption and air pollution [10].

Applying vernacular strategies in hot and humid regions of Iran as a model for designing contemporary houses for such climates can lead to optimal energy consumption and improved levels of comfort [11]. This article aims to identify and analyze climate-responsive solutions used in dwellings of Dezful city by examining these solutions and their effect on thermal comfort and energy consumption of these dwellings compared to contemporary buildings.

Masoumi [12] worked on a vernacular urban form, which has been designed before the arrival of mechanical heating and cooling in Bushehr as a case study. Their results reveal the appropriate geometry, proportions, and orientation of masses and open spaces to improve the natural ventilation in compact urban form. Other studies were also conducted by Ranjbar [13], Mohammadi [14], Nikghadam [15], Motealleh [16], Shahmortezaei et al. [17] and Hazbei [18] in the cities located in hot and humid regions of Iran including Bushehr and Dezful which identified and examined the most important passive and vernacular solutions in traditional building existing in the historical texture of these cities by field study and simulation and recommended using these strategies in contemporary buildings. However, they didn't mention the effect of these strategies on internal thermal comfort conditions and energy consumption in traditional dwellings.

The main achievement of this research is the formulation of a structured and measurable method whose final results can be used to measure the impact of each strategy and model. Provides software for any complexity and compares it to the designer and the employer, the power of data validation and the power to select patterns are two of the most important findings of this research.

\section{Research Methodology}

The present study is an applied research in terms of the purpose and is a qualitative research in terms of its nature. This research is based on the library methodology to examine the resources and field observations for model extraction and observation and observation in space. Research is based on systematic and evidence-based analysis. The method of data analysis will be based on the coding method.

\subsection{Case Study}

Dezful is located in the province of Khuzestan, in south west of Iran in $+32^{\circ}, 25^{\circ}$ latitude and $+48^{\circ}, 25^{\circ}$ eastward longitude [19] Behind this region (Dezful) is the Zagros chain of mountains and before it lies the plains of Khuzestan which extends as far as the Persian Gulf. Thus it has an ecological situation between the central desert of the Kavir cities and the coastal regions of Persian Gulf cities. Temperature in the summer time rises to more than $50^{\circ}$ above zero. Since its distance is rather far from Persian Gulf $(250 \mathrm{~km})$ the humidity is less. So, it has warm and semi humid climate. Climatic factors such as the intensity and direction of the sun, heat, weather and favorable wind direction and natural and topographic factors have an important role in the formation and stability of complex old Dezful, this city was built on a type of Conglomerate rising above the Dezz river surface and the river in this city has always had clear and cold running water from the Zagros chain of mountains.

\subsection{Climate Consultant Software}

Designing and remodeling buildings that are truly climate responsive depends first on gaining a detailed accurate understanding of the local climate. Climate consultant reads the local climate data in EPW (Energy Plus Weather) format 
and displays dozens of different graphic charts of various weather attributes. The purpose of climate consultant is not simply to plot climate data, but rather to organize and represent this information in easy to understand new ways that reveal the subtle attributes of climate and its impact on built form.

\section{Analysis of Climate Parameters}

\subsection{The Temperature Range}

This chart is the simplest chart and shows the temperature range of the air in different months of the year. Each cylinder shows the temperature of the air in each month of the year. This is the simplest of all charts and shows the dry bulb temperature ranges enclosing the Recorded High and Low Temperature (round dots), the Design High and Low Temperatures (top and bottom of green bars), average High and Low Temperatures (top and bottom of yellow bars), and Mean or Average Temperature (open slot).

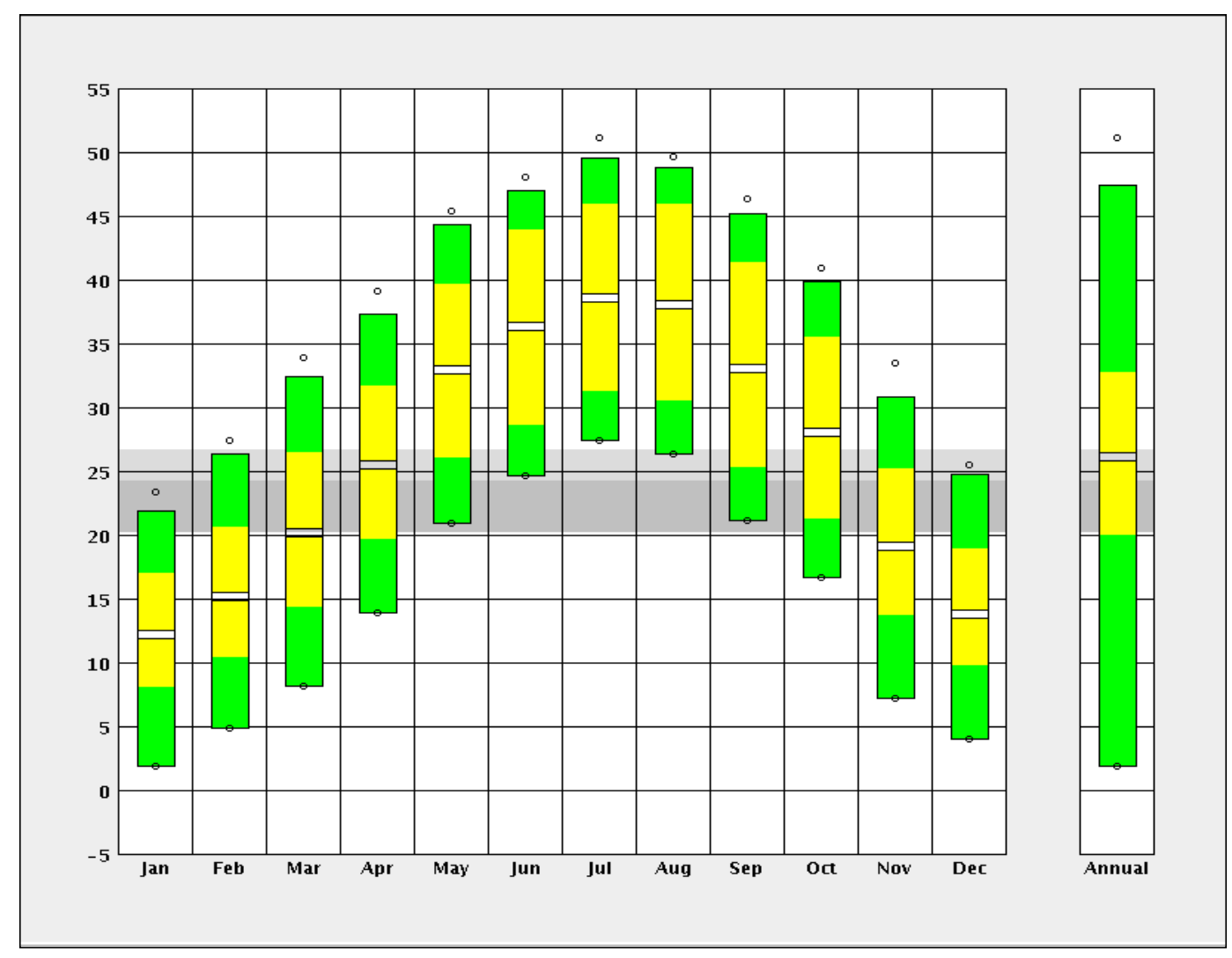

Figure 1. The Temperature Range (climate consultant software)

These values are calculated for each month and for the full year by climate consultant. Semi top area of the gray color is the comfort temperature in the winter and the Under Area of gray Color shows low temperature, comfort in the summer. Whenever the midline of the cylinders above the gray line represents the warm months that are considered in this summer note and whenever the cylindrical of the months are under the middle of the gray line that is winter (Figure1).

According to the above-mentioned studies and the chart, the results obtained, we conclude that April, May, June, July, August, September and October is the summer season and the rest of the winter months. The chart below shows the results obtained.

\subsection{Monthly Average Temperature}

For each month of the year this chart shows the diurnal (24 hour) average data for each hour of each month. It shows the average Dry Bulb Temperature (upper red curve) and average Wet Bulb Temperature (lower red curve) against a grey bar that represents the comfort range as defined on the Criteria Screen, all in degrees F (degrees C). If you click on the box that says Display Hourly Dry Bulb Temperatures then the temperature for every hour of the day throughout the year will be shown in light blue underlain behind the average dry bulb temperature curves. The Average Hourly Radiation for each month is indicated on the left hand scale in Btu/sq.ft (Wh/sq.m) and is shown in green for Global Horizontal, in yellow for Direct Normal, and in blue for Diffuse Radiation. When Diffuse Radiation is higher, it usually means that the sky is more overcast and so Direct Normal Beam Radiation will probably be cut down, thus Total or Global Horizontal Radiation will be reduced. Global Horizontal Radiation is the sum of Diffuse Radiation from the 
entire sky vault plus Direct Normal Radiation from the sun times the cosine of its angle of incidence to the ground.

In the city of Dezful, only in the months of October and April, there are night and day warming conditions, and there were some thermal conditions on the nights of August and September and July.

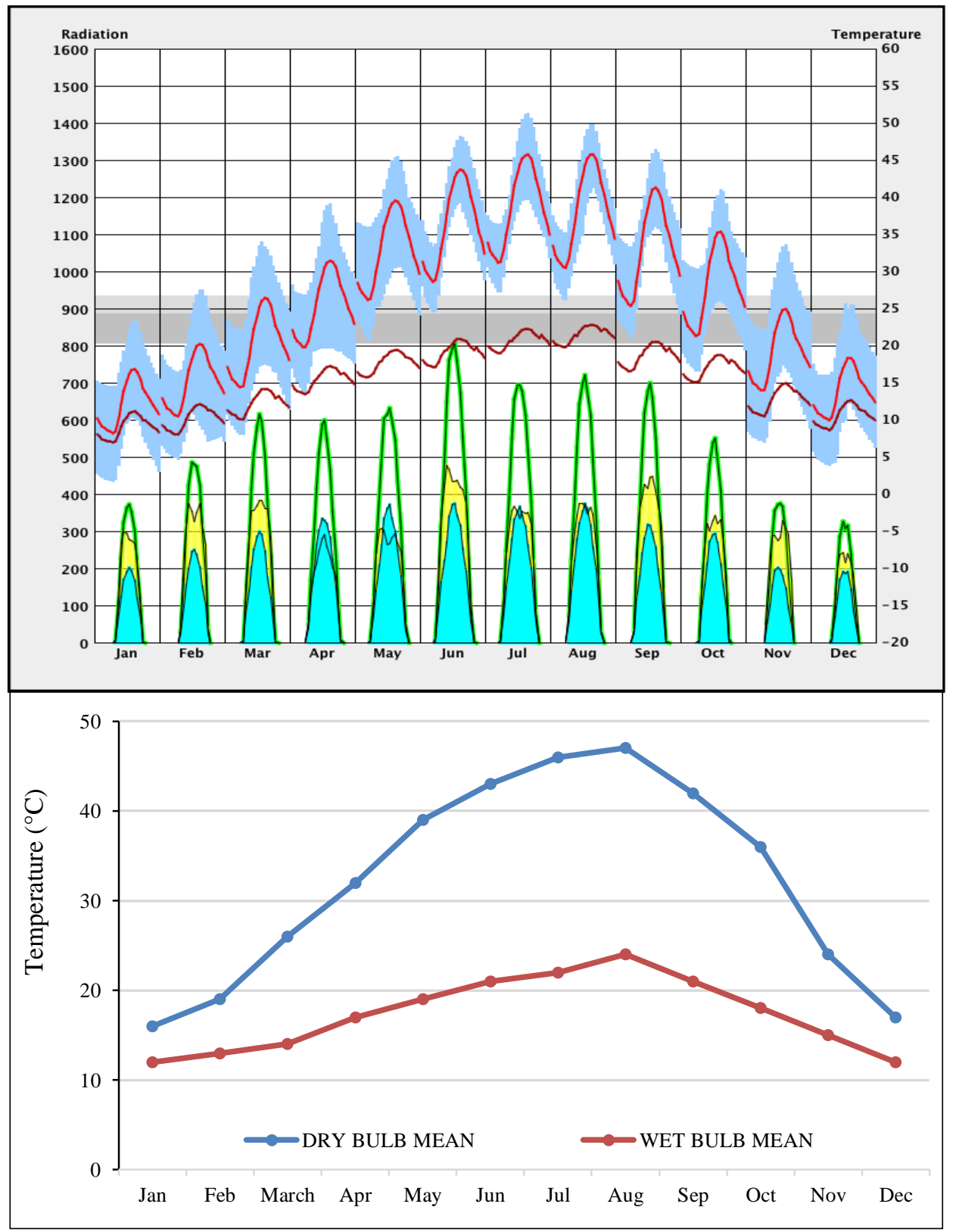

Figure 2. Monthly average temperature (climate consultant software)

Figure 2 in the months of May, July, June, August and September, we are in very severe conditions (very hot), and in January, February, March, November and Desmond there is a very cold air. In the city of Dezful, in the months of October and April, the thermal conditions were around the clock, and on the nights of August and September and July, thermal conditions were somewhat provided. In the months of May, July, June, August, and September, we are in extreme conditions due to the warmth of the day, and in January, February, March, November, and December there is a lot of cold weather.

\subsection{Dry Bulb vs. Relative Humidity}

These 12 charts are the average for each hour of each month of the Dry Bulb Temperature (yellow dot) and the concurrent Relative Humidity (green dot). Also shown on each monthly chart is a gray bar for the Comfort Zone as defined on the Criteria screen. Notice that dry bulb temperature is almost exactly the inverse of relative humidity. 
Table 1. Dry Bulb vs. Relative Humidity

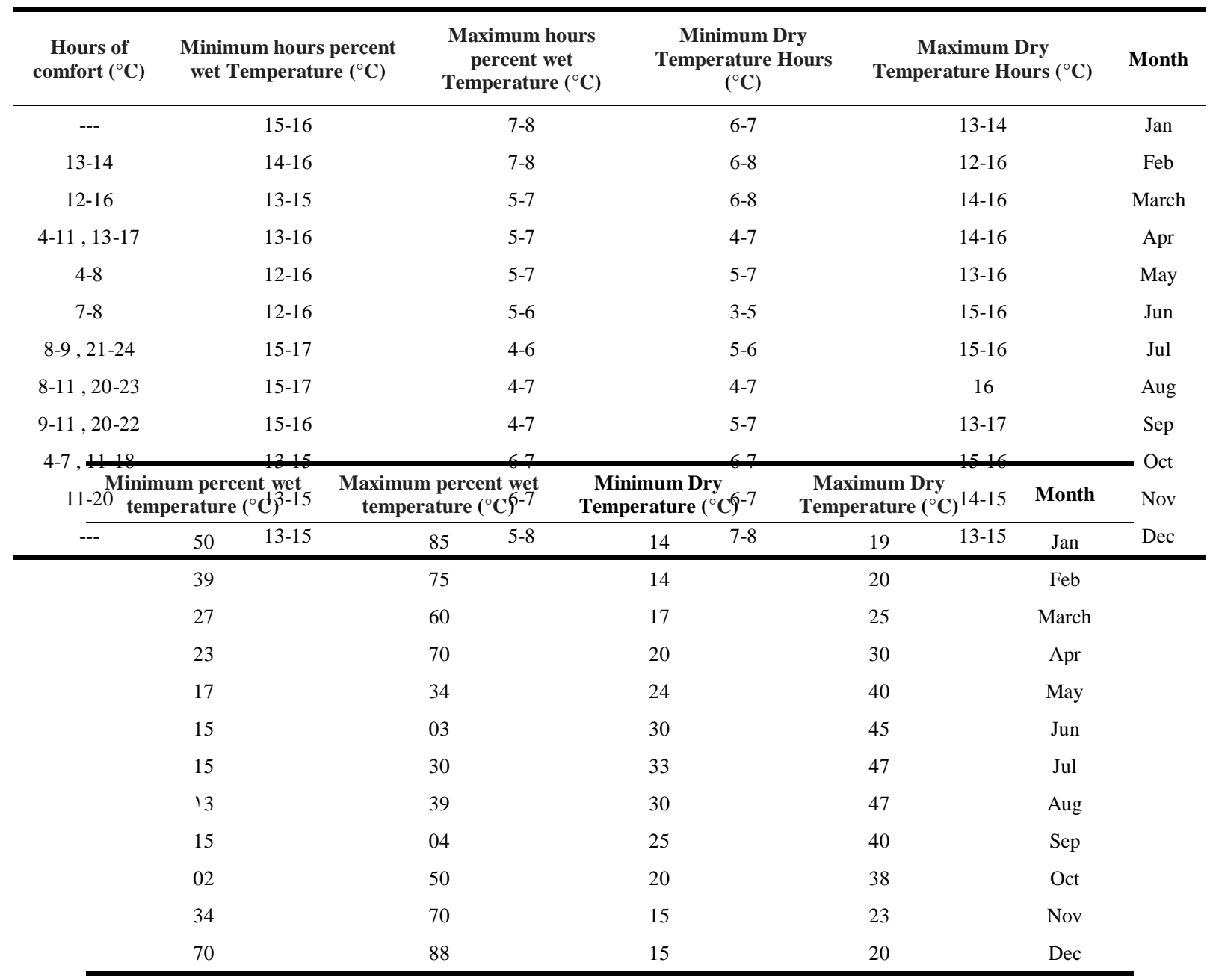

\begin{tabular}{|c|c|c|}
\hline Hour & Degree of temperature & moisture percent \\
\hline 4 & 15 & 80 \\
\hline 8 & 15 & 85 \\
\hline 12 & 18 & 58 \\
\hline 16 & 19 & 50 \\
\hline 20 & 17 & 63 \\
\hline 24 & 15 & 70 \\
\hline Average & 17 & 68 \\
\hline JAN & & \\
\hline
\end{tabular}

\begin{tabular}{|c|c|c|}
\hline Hour & Degree of temperature & moisture percen \\
\hline 4 & 17 & 70 \\
\hline 8 & 18 & 75 \\
\hline 12 & 19 & 43 \\
\hline 16 & 20 & 40 \\
\hline 20 & 18 & 57 \\
\hline 24 & 16 & 60 \\
\hline Average & 18 & 58 \\
\hline
\end{tabular}

\begin{tabular}{|c|c|c|}
\hline Hour & Degree of temperature & moisture percent \\
\hline 4 & 17 & 58 \\
\hline 8 & 19 & 55 \\
\hline 12 & 23 & 27 \\
\hline 16 & 25 & 25 \\
\hline 20 & 21 & 38 \\
\hline 24 & 19 & 47 \\
\hline Average & 21 & 42 \\
\hline MARCH & & \\
\hline
\end{tabular}




\begin{tabular}{|c|c|c|}
\hline Hour & Degree of temperature & moisture percent \\
\hline 4 & 20 & 48 \\
\hline 8 & 24 & 41 \\
\hline 12 & 30 & 28 \\
\hline 16 & 32 & 27 \\
\hline 20 & 24 & 35 \\
\hline 24 & 23 & 42 \\
\hline Average & 26 & 37 \\
\hline APR & & \\
\hline
\end{tabular}

\begin{tabular}{|c|c|c|}
\hline Hour & Degree of temperature & moisture percent \\
\hline 4 & 25 & 30 \\
\hline 8 & 30 & 25 \\
\hline 12 & 38 & 17 \\
\hline 16 & 40 & 16 \\
\hline 20 & 37 & 20 \\
\hline 24 & 31 & 28 \\
\hline Average & 34 & 23 \\
\hline MAY & & \\
\hline
\end{tabular}

\begin{tabular}{|c|c|c|}
\hline Hour & Degree of temperature & moisture percent \\
\hline 4 & 15 & 15 \\
\hline 8 & 38 & 27 \\
\hline 12 & 41 & 17 \\
\hline 16 & 43 & 17 \\
\hline 20 & 40 & 18 \\
\hline 24 & 30 & 26 \\
\hline Average & 35 & 20 \\
\hline JUN & & \\
\hline
\end{tabular}

\begin{tabular}{|c|c|c|}
\hline Hour & Degree of temperature & moisture percent \\
\hline 4 & 23 & 50 \\
\hline 8 & 25 & 45 \\
\hline 12 & 36 & 24 \\
\hline 16 & 38 & 20 \\
\hline 20 & 30 & 32 \\
\hline 24 & 25 & 40 \\
\hline Average & 30 & 35 \\
\hline
\end{tabular}

\begin{tabular}{|c|c|c|}
\hline Hour & Degree of temperature & moisture percent \\
\hline 4 & 17 & 63 \\
\hline 8 & 18 & 62 \\
\hline 12 & 23 & 38 \\
\hline 16 & 25 & 37 \\
\hline 20 & 20 & 48 \\
\hline 24 & 18 & 56 \\
\hline Average & 20 & 51 \\
\hline
\end{tabular}

\begin{tabular}{|c|c|c|}
\hline Hour & Degree of temperature & moisture percent \\
\hline 4 & 16 & 81 \\
\hline 8 & 15 & 85 \\
\hline 12 & 19 & 58 \\
\hline 16 & 19 & 53 \\
\hline 20 & 17 & 66 \\
\hline 24 & 18 & 77 \\
\hline Average & 17 & 70 \\
\hline
\end{tabular}

Table1 Comfort conditions of the day:

In the city of Dezful, from April to December of the morning, the comfort conditions are somewhat available, and there are some comfort conditions available in the months of February, March and April.

Comfort conditions at night:

In the city of Dezful, from July to December at night, there are almost comfortable conditions.

Monthly comfort conditions:

- In the months of January, February and March at night, there is a feeling of comfort, but days are heavy.

- The comfort of the day is not maintained in April-June, and it suffers from extreme heat, which is favorable on the nights of April and is warm in the months of May and June.

- From July to October, day and night weather is warm and has high humidity.

- In October and November, there were almost comfortable conditions, and in December we did not have comfortable conditions due to relative humidity.

\subsection{Radiation Range}

The Hourly Averages Chart shows for each month and for the full year, the Direct Normal Solar Radiation (yellow), Global (Total) Horizontal Solar Radiation (green), and Tilted Surface Radiation (orange) for all daylight hours. Using ASHRAE formulas Climate Consultant calculates the Theoretical maximum hour during each month for both Direct Normal and Global Radiation and displays it as the solid black line. The Recorded (or Peak) highest hour of radiation in the EPW data file is shown as a small colored circle. The Average High is the average of the highest value from each day of the month or annually and is shown as the top of the colored bar. The Mean or average of all the daylight hours is shown as the break in the colored bar. The Average Low value is the average of all the lowest values of the month during daylight hours. And the Recorded Low value will represent the lowest radiation in the EPW file data file during that month between sunrise and sunset. Note that the Recorded Low Global Horizontal Radiation might be greater than zero because of sky glow that is recorded just before the sun rises or just after it sets.

The Daily Total Radiation is the total Radiation for each day of the month showing the highest day of the month, the lowest day, and the mean or average day of the month. The units are in Btu/sq.ft. or Wh/sq.m ( Figure3).

It should be kept in mind that the registration of the global base of radiation is greater than the horizontal radiance since the glow of the sky (the light of the sky) just before sunrise or after sunset causes this error, that is, when the radiation is absorbed by the surface begins Which the sun raises and radiates until it sets aside.

According to the information explanation, this diagram is extracted and presented in the form of tables. 


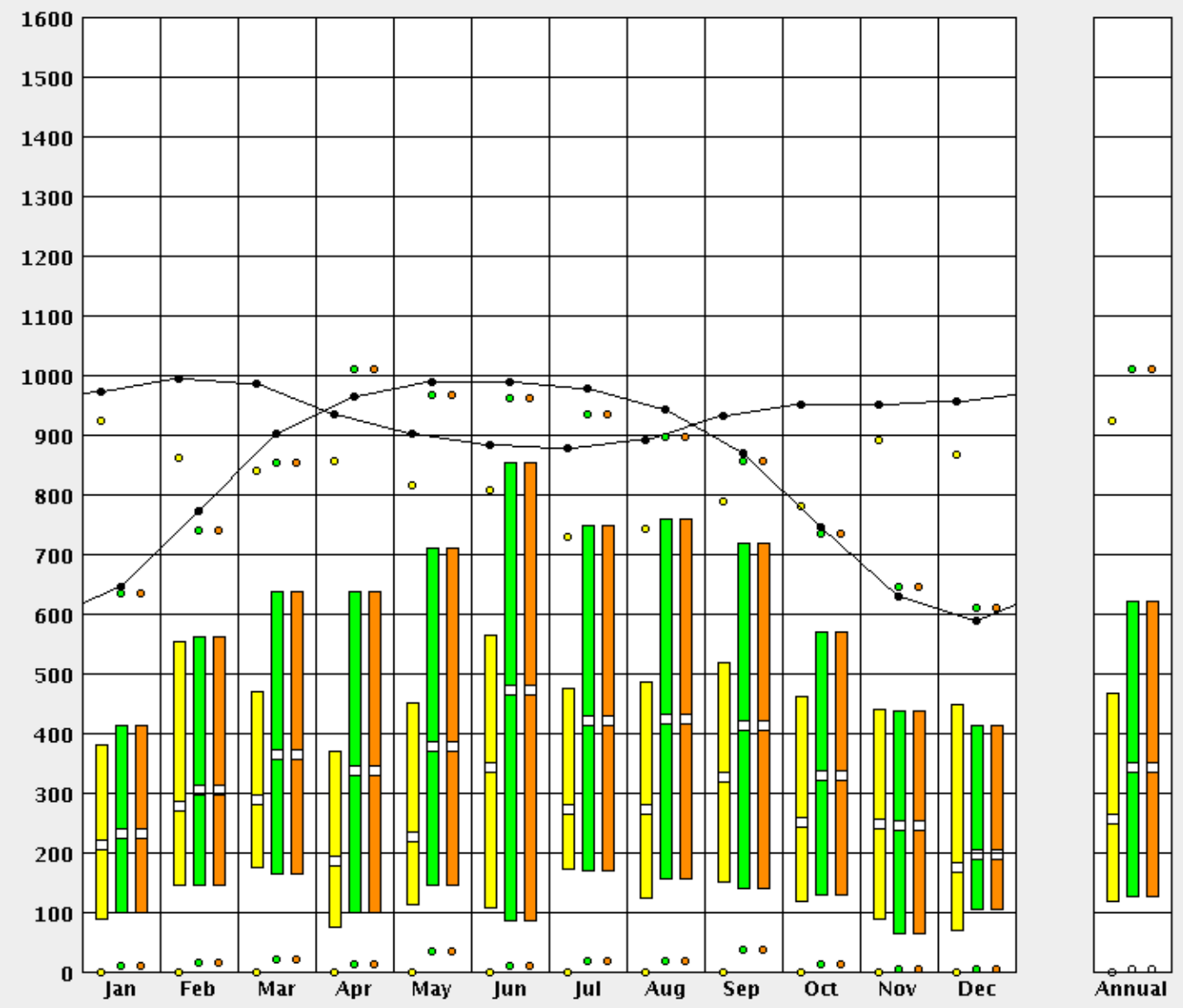

Figure 3. Radiation Range (climate consultant software)

Table 2. Radiation Range (climate consultant software)

\begin{tabular}{|c|c|c|c|c|c|c|c|c|c|c|c|c|c|c|c|c|}
\hline Angels (deg) & & winter & & & & & nmer & & & & wir & & & Ave & rage & \\
\hline $\begin{array}{c}15 \\
105 \\
-75 \\
-165\end{array}$ & Jan & Feb & Mar & Apr & May & Jun & Jul & Aug & Sep & Oct & Nov & Dec & $\begin{array}{c}\text { Avr } \\
\text { W }\end{array}$ & $\begin{array}{c}\text { Avr } \\
\text { S }\end{array}$ & $\begin{array}{l}\text { Avr } \\
\text { W.T }\end{array}$ & $\begin{array}{l}\text { Avr } \\
\text { S.T }\end{array}$ \\
\hline Total & 410 & 560 & 620 & 620 & 710 & 850 & 730 & 730 & 710 & 580 & 410 & 410 & 643 & 956 & - & - \\
\hline North (-165) & 0 & 0 & 0 & 50 & 110 & 180 & 120 & 90 & 10 & 0 & 0 & 0 & 92.8 & 0 & 229.5 & 259.2 \\
\hline South (15) & 390 & 480 & 390 & 280 & 270 & 260 & 270 & 260 & 300 & 400 & 400 & 410 & 291.4 & 340 & 229.5 & 259.2 \\
\hline West (105) & 210 & 340 & 380 & 280 & 330 & 480 & 410 & 410 & 400 & 300 & 250 & 180 & 272 & 373 & 229.5 & 259.2 \\
\hline East (-75) & 210 & 300 & 310 & 270 & 310 & 390 & 300 & 320 & 370 & 310 & 280 & 210 & 262 & 324.2 & 229.5 & 259.2 \\
\hline
\end{tabular}

Table 2 the method of investigation is this: the building rotates 15 times 30, 45 and 180 degrees Clock wise each time. The numbers that show the amount of radiation in the table are obtained. Forconvenience, the comparison between the numbers from each row is graded to average numbers (given thehigh number of charts and tables extracted only the selected table will be presented). By comparing the total radiation per month, optimal conditions can be obtained. To find the direction of the building every month. 
Example: the average total radiation absorption in the summer of 704 and in the winter of 485 , but in the 15 degrees of time, is $259.2 \mathrm{Wh} / \mathrm{sq} . \mathrm{m}$ and $229.5 \mathrm{Wh} / \mathrm{sq} . \mathrm{m}$, by comparing the numbers in qualitative terms, it is found that with 15 degrees of time, the absorbed radiation of the sun can be up to Halved, but reduced to about half the absorbed radiation in the winter, which is not favorable due to the relatively cold winters we see on the basis of software data in our climate. Based on surveys and comparisons, the best angle for building angle of 30 degrees is.

\subsection{Shading Chart}

This chart shows the sun's bearing (along the bottom) and altitude (vertically) for every 15 minutes during the year in colored dots. Yellow dots indicate comfort conditions when the Dry Bulb temperature is within the comfort zone as defined on the Criteria Screen. Red dots indicate overheat conditions when the Dry Bulb temperature is above the top of the comfort range. Blue dots indicate under heat conditions when dry bulb temperatures are below the bottom of the comfort zone. Ideally for passive heating the windows should be fully exposed wherever there are blue dots, and to prevent overheating windows should be fully shaded wherever there are red or yellow dots.

Two options on the Sun Shading Chart legend allow the user to define shading masks or fins and overhangs (Display Shading Calculator) and shading overlays for remote objects (Display Obstruction Elevation). Based on whether or not these overlays are displayed, the Sun Shading Chart legend displays the number of unshaded hours during cool season when solar gain is desirable, during the hot season when shading is definitely desirable, and during the comfort hours when solar gain is not needed. For example, if neither overlay is displayed, all hours are assumed to be shaded.

If just the Shading Calculator is displayed, just those hours masked by fins and the overhang are assumed to be shaded. If just the Obstruction Elevation overlay is displayed, the hours covered by the vertical bars representing shading objects are assumed to be shaded. If both the Shading Calculator and the Obstruction Elevation overlay are displayed, all hours shade by one and the other or both are counted (hours are not counted twice).

Bibliography: the best diagrams explaining how to use this chart to design Fins or Overhangs is in Mazria (see Shading Calculator). Lechner shows how it can account for nearby trees and buildings.

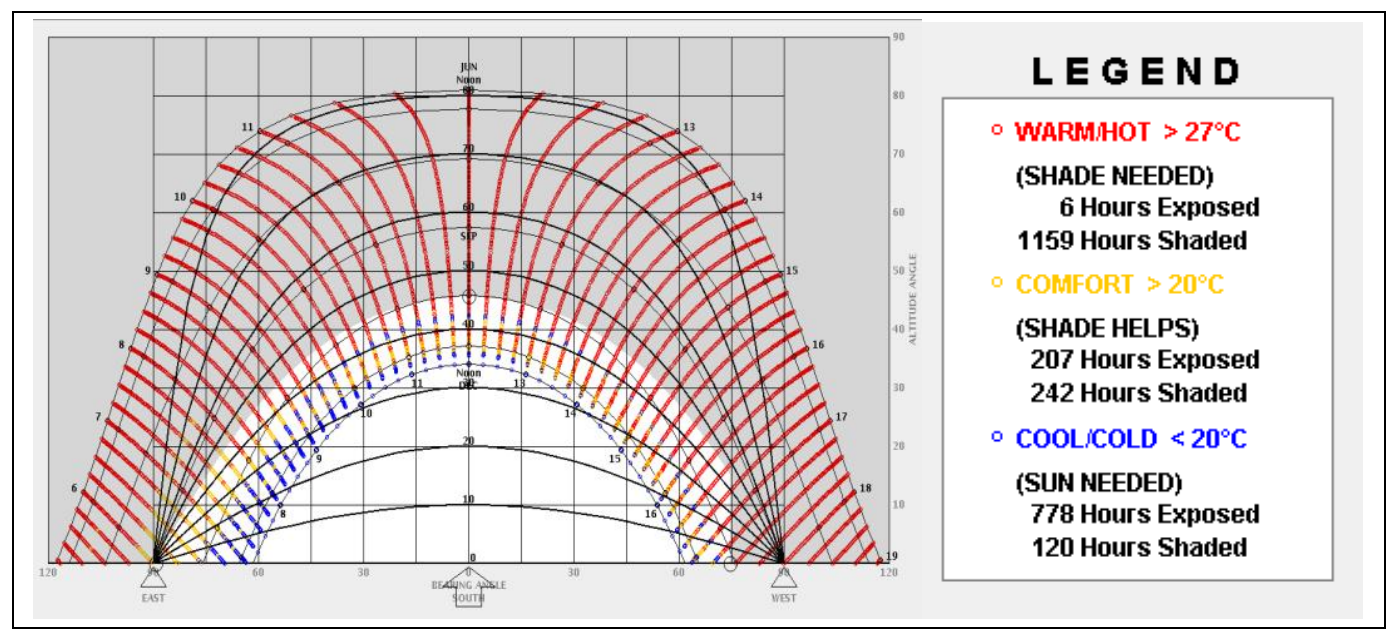

Figure 4. Sun Shading Chart (climate consultant software)

Figure 4. Autumn and Winter:

Dezful has 738 dots that are open and need a canopy and 389 dots in comfort conditions, however, it is better to use a canopy for them, as well as 867 dots that are cool and do not require a shadow.

Spring and Summer:

In Dezful 1372 there are dots that are open and need to have a canopy and 265 dots in comfort conditions, which is better to use the canopy, and there are also 355 dots that are very cold and require sunlight.

Result:

Optimum mode in Dezful is the use of a horizontal 55 degree canopy and a vertical canopy facing the west with a 60 degree angle.

\subsection{Temperature Plot}

This plot shows along the bottom the months of the year and along the side the hours of the day. The time when Sunrise and Sunset occurs for this latitude is indicated by the curved yellow lines. Eleven different variables can be plotted by selecting from the box in the lower left: Dry Bulb Temperature, Wet Bulb Temperature, Depression (difference between Dry Bulb and Wet Bulb Temperatures), Relative Humidity, Wind Speed, Global Horizontal 
Radiation, Direct Normal Radiation, Tilted Surface Radiation, Global Horizontal Illumination, Direct Normal Illumination, and Sky Cover. The units for each variable are indicated in the upper left, divided into five different ranges in colors from blue to red, and the percentages of hours that fall in each range are also shown. The colors plotted can be changed by the user by clicking on a colored square in the Legend. In the bottom left, the plot can be changed from Daily (which shows each of the 8760 hours per year) to Monthly Averages (which shows the average for each hour of the month). When the Tilted Surface Radiation plot is displayed, the user can modify the Tilt Angle and Bearing of the surface as well as the Ground Reflectance factor. The Dry Bulb Temperature plot was initially named by Olgyay as the Timetable of Bioclimatic Needs and was used in his text to display graphically the differences between different types of climates. It also shows in the darkest blues when sun-facing windows should be exposed for passive heating and in light blue and red when windows should be shaded (Figure 5).
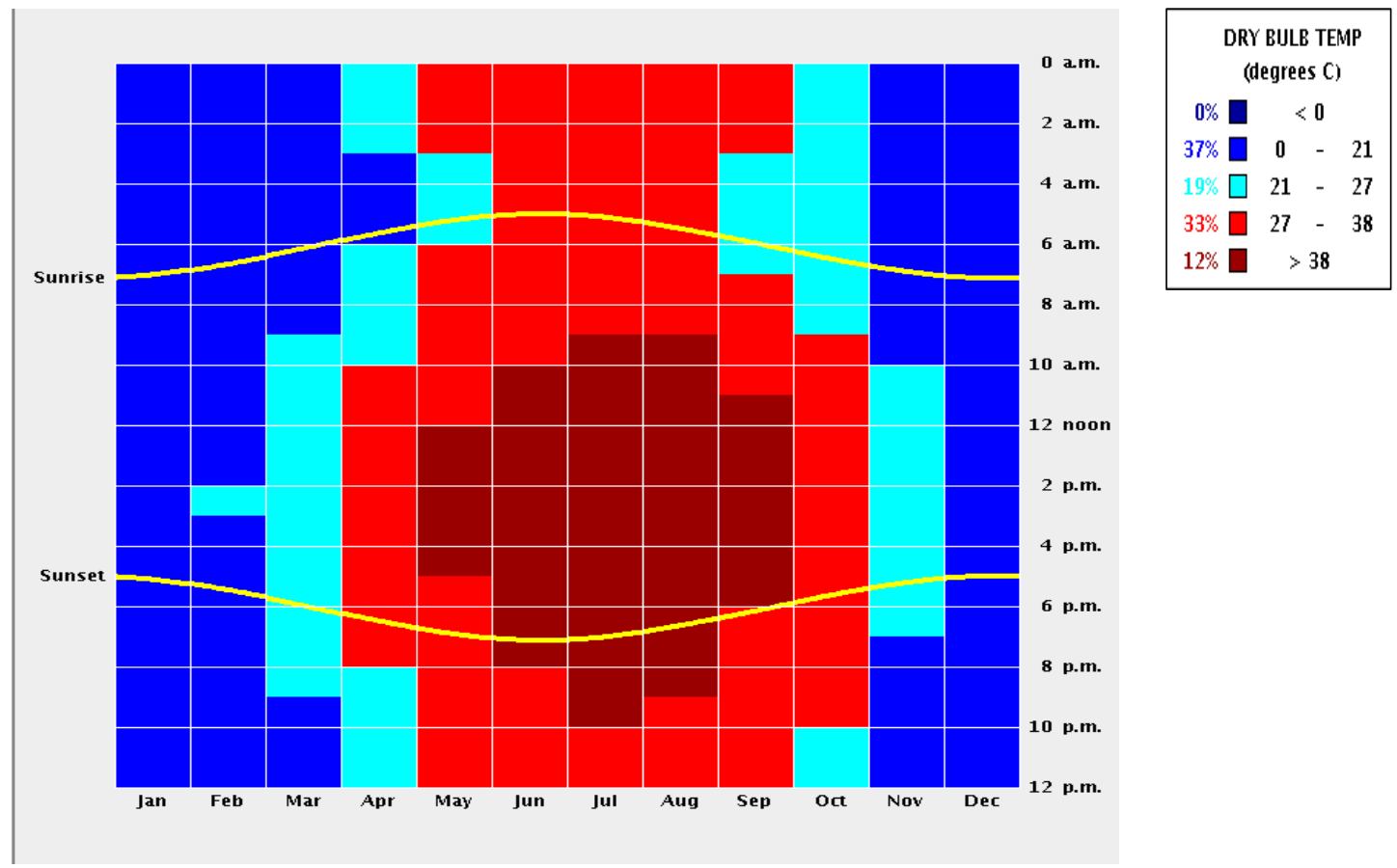

Figure 5. Temperature Plot (climate consultant software)

\begin{tabular}{|c|c|c|c|c|c|}
\hline & $<0$ & $0-21$ & $21-27$ & $27-38$ & $>38$ \\
\hline Jun & $0-24$ & - & - & - & - \\
\hline Feb & $0-14 / 15-24$ & $14-15$ & - & - & - \\
\hline Mar & $21-9$ & $9-21$ & - & - & - \\
\hline Nov & $19-10$ & $12-19$ & - & - & - \\
\hline Dec & $0-24$ & - & - & - & - \\
\hline
\end{tabular}

Winter

\begin{tabular}{|c|c|c|c|c|c|}
\hline & $<0$ & $0-21$ & $21-27$ & $27-38$ & $>38$ \\
\hline Apr & - & $3-6$ & $20-3$ & $17-1 / 6-12$ & - \\
\hline May & - & - & $1-6$ & $17-3 / 6-12$ & $0-5$ \\
\hline Jun & - & - & - & $20-10$ & $10-20$ \\
\hline Jul & - & - & - & $22-9$ & $9-22$ \\
\hline Aug & - & - & - & $21-9$ & $9-21$ \\
\hline Sep & - & - & $1-5$ & $7-11 / 18-3$ & $11-18$ \\
\hline Oct & - & - & $22-9$ & $9-22$ & - \\
\hline
\end{tabular}

Summer

Table 3. Temperature Plot

In this section, temperature graphs are indicated by temperature graphs during the months of the year and at midday. The logic of this timeline shows that sunrise and sunset occur for this latitude, with curved yellow lines. The units of each variable are shown in the upper left-hand side and are divided into five different colors from blue to red, and the percentage of hours in each range is shown. Mainly, with the aid of this diagram, the temperature range can be checked at different hours of the day in different months, which is more precisely studied in the field of temperature measurement. The extracted information is presented in the form of a table to help them analyze and use them. This chart is analyzed as seasonally in the form of 2 seasons of summer and winter, and the data is presented in the form of a table (Table 3 ).

\subsection{Psychrometric Chart}

This chart is one of the most powerful design tools in Climate Consultant. It shows dry bulb temperature across the 
bottom and moisture content of the air up the side. This vertical scale is also called absolute Humidity and can be shown as the humidity ratio in pounds of water per pound of dry air (or grams of water Per kilogram of dry air), or as the vapor pressure. The curved line on the far left is the saturation line (100\% Relative Humidity line) which represents the fact that at lower temperatures air can hold less moisture than at higher temperatures. Every hour in the EPW climate data file is shown as a dot on this chart. Notice that some dots may represent more than one hour, for example when a given temperature and humidity occurs more than once in any month.

Notice also that a given hour's dot might meet the criteria for more than one strategy zone, in which case it is counted in the Percentage of Hours for both zones, which is why the percentages add up to more than 100\%. A tutorial explaining the other lines on this chart and how to use it as a design tool is available at: www.energy-design-tools.aud.ucla.edu. The color of each dot can represent whether or not the hour is Comfortable (green) or Uncomfortable (red), according to the inputs defining Comfort on the Criteria screen. Four other Plot options are available on the left hand Legend panel, each plotting hourly data in a range of colors. These other Plot options are Dry Bulb Temperature, Global Horizontal Radiation, Sky Cover, and Wind Speed. The units for each variable are indicated in the upper left. The values for each variable are divided into five different ranges which are plotted in colors from blue to red, or if the plot represents Comfort there are just two colors: dark green is comfortable, red is not comfortable.

The percentages of hours that fall in each category are also shown. Another plot option is to show just the Daily Minimum and Maximum hour for each day with a line drawn between, the length of which shows the daily temperature difference (diurnal delta T). The next option on the left hand panel allows you to display All Hours during the day or just Selected Hours. The next option allows you to display either All Months of the Year, or Selected Months, or any Single Month, with a box that lets you click through the months selected. Another new option allows you to select a single day of the selected month. All hours for that day are plotted in sequence with a line connecting the points. This allows you to see in fine grain the daily evolution of temperature and humidity.

The Chart itself can be adjusted with a fixed Temperature Range or Fit to the Data. The next to last option on the left side is to turn on or off the Display of Design Strategies. The last option is to Show the Best Set of Design Strategies, which will use an algorithm that selects from among similar strategies the smallest set that eliminates the greatest number of Heating and Cooling hours. You can click on any Strategy to turn it on or off to test other combinations that might be more appropriate for your particular building in your particular climate (Figure 6).

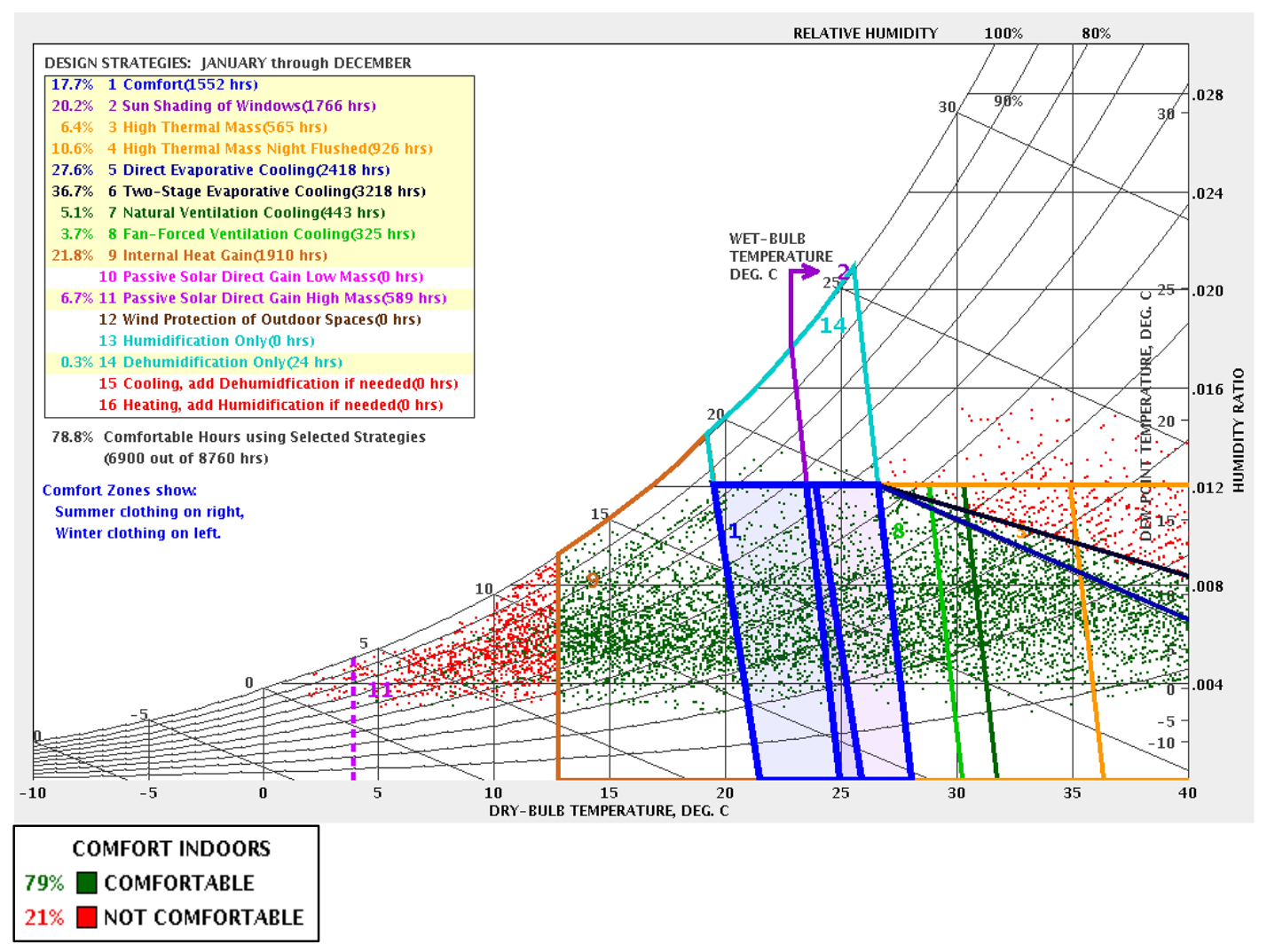

Figure 6. Psychrometric (climate consultant software) 
Table 4. Psychrometric Parameters (climate consultant software)

\begin{tabular}{ccc}
\hline \multicolumn{2}{c}{ Design Dynamic Strategies January through December } \\
\hline Strategies & Time in 1 Year & Percent of all days In The Year \\
\hline Cooling, add Dehumidfication & $932 \mathrm{hrs}$ & $10.6 \%$ \\
Heating, Add Humidification & $928 \mathrm{hrs}$ & $10.6 \%$ \\
\hline \multicolumn{1}{c}{ Design Static Strategies January through December } \\
\hline Strategies & Time in 1 Year & Percent of all days In The Year \\
Comfort & $1552 \mathrm{hrs}$ & $17.7 \%$ \\
Sun Shading Of windows & $1766 \mathrm{hrs}$ & $20.2 \%$ \\
High Thermal Mass & $565 \mathrm{hrs}$ & $6.4 \%$ \\
High Thermal Mass Night Flushed & $926 \mathrm{hrs}$ & $10.6 \%$ \\
Direct Evaporative Cooling & $2418 \mathrm{hrs}$ & $27.6 \%$ \\
Two- Stage Evaporative Cooling & $3218 \mathrm{hrs}$ & $36.7 \%$ \\
Natural Ventilation Cooling & $443 \mathrm{hrs}$ & $5.1 \%$ \\
Fan-Forced Ventilation Cooling & $325 \mathrm{hrs}$ & $3.7 \%$ \\
Internal Heat Gain & $1910 \mathrm{hrs}$ & $21.8 \%$ \\
Passive Solar Direct Gain High Mass & $589 \mathrm{hrs}$ & $6.7 \%$ \\
Dehumidification Only & $24 \mathrm{hrs}$ & $0.3 \%$ \\
\hline 78.8\% Comfortable Hours Using Selected Strategies \\
\hline
\end{tabular}

Table 4 In the whole of the year, due to the very hot summers and relatively cold winters, it is difficult to provide comfortable conditions that can be achieved by taking the measures up to $78.8 \%$. According to a temperature analysis in Dezful, creating comfortable conditions in the summer is more important than the comfort conditions of the winter season. In the tables below, the effects of each section are shown, the tables show how much each strategy can help us to create comfort conditions.

\subsection{Wind Wheel}

The Wind Wheel is unique to Climate Consultant. It displays for each wind direction the Wind Velocity and Frequency of Occurrence along with concurrent average Dry Bulb Temperature and Relative Humidity. The outer ring shows the percentage of hours when the wind comes from each direction. On the next ring the height and color of the bars shows the average temperature of the wind coming from that direction (light blue is in the comfort zone, blue is cool or cold, and red is warm or hot). The next smaller ring shows average humidity (light green is comfortable, yellow is dry, and green is humid). The innermost circle shows the wind velocities that come from each direction; the tallest brown triangle is the maximum velocity for that period, medium brown is the average velocity, and the smallest light brown triangle is the minimum velocity. Hours when there is zero wind speed do not appear on this chart. The graphic key to all this information is summarized in the icon in the lower right labeled Wind Speed, RH, Temp, and Hours. Some weather stations report wind direction only within wide categories, which accounts for the white or empty wind direction zones on some charts (Figure 7). 


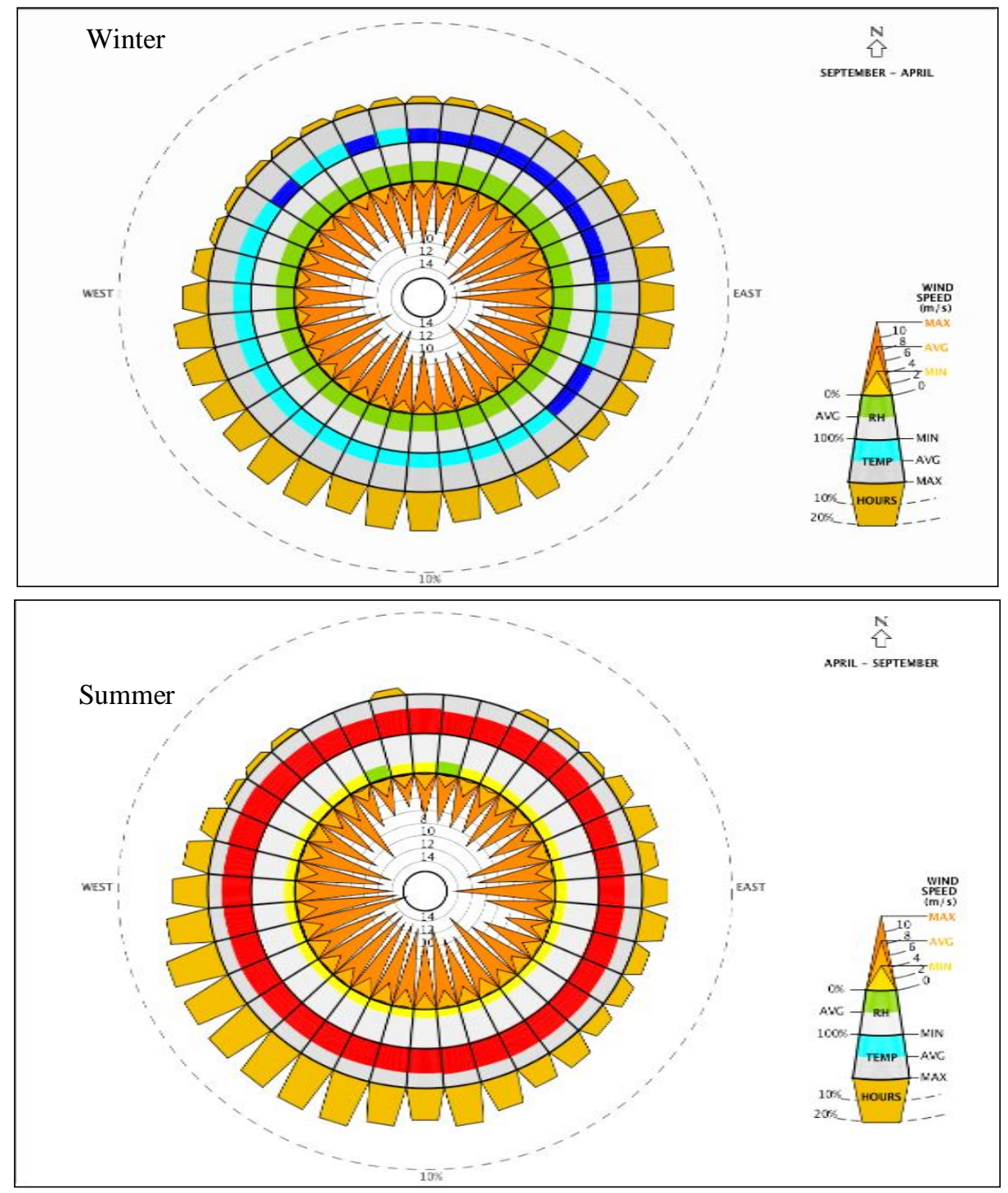

\begin{tabular}{|l} 
TEMPERATURE (Deg. C) \\
$<0$ \\
$<-21$ \\
$0-21-27$ \\
$\square 27-38$ \\
$\square>38$ \\
$\square$ \\
RELATIVE HUMIDITY $\%$ ) \\
$\square<30$ \\
$\square 30-70$ \\
$\square>70$
\end{tabular}

Figure 7. Wind Wheel (climate consultant software)

Table 5. Wind Wheel in summer (climate consultant software)

\begin{tabular}{ccccccc}
\hline Direction & Hours & Temp & Rh & $\begin{array}{c}\text { speed Min } \\
(\mathbf{m} / \mathbf{s})\end{array}$ & $\begin{array}{c}\text { Speed } \\
\text { Max }(\mathrm{m} / \mathrm{s})\end{array}$ & $\begin{array}{c}\text { Speed } \\
\text { Ave }(\mathrm{m} / \mathbf{s})\end{array}$ \\
\hline & $4 \%$ & $0-21$ & $30-70$ & 2 & 13 & 2 \\
& $4 \%$ & $0-21$ & $30-71$ & 2 & 10 & 3 \\
& $6 \%$ & $0-21$ & $30-72$ & 1 & 12 & 2 \\
& $4 \%$ & $0-21$ & $30-73$ & 1 & 14 & 1 \\
\hline
\end{tabular}


Table 6. Wind Wheel in winter (climate consultant software)

\begin{tabular}{ccccccc}
\hline Direction & Hours & Temp & Rh & $\begin{array}{c}\text { speed Min } \\
(\mathbf{m} / \mathbf{s})\end{array}$ & $\begin{array}{c}\text { Speed Max } \\
(\mathbf{m} / \mathbf{s})\end{array}$ & $\begin{array}{c}\text { Speed Ave } \\
(\mathbf{m} / \mathbf{s})\end{array}$ \\
\hline & $7 \%$ & $27-38$ & $0<30$ & 2 & 16 & 4 \\
& $8 \%$ & $27-38$ & $0<30$ & 2 & 14 & 4 \\
& $8 \%$ & $27-38$ & $0<30$ & 1 & 12 & 4 \\
& $3 \%$ & $27-38$ & $0<30$ & 2 & 16 & 4 \\
\hline
\end{tabular}

Table 5, 6. by checking options such as wind speed, wind speed, wind speed, humidity and wind, you can check the wind conditions of the city of Dezful in all months of the year. At first, the wind was thoroughly examined throughout the year and then examined in the summer. Regarding the importance of ventilation in summer, first summer and then winter were investigated. In each section the table is indicated for frequency, temperature, humidity and average speed. In the summer, the winds of the southwest and south are favorable (speed, frequency, and temperature).

\section{Conclusion}

The analysis of climate data shows the short duration of the climate and climate of the two summer hot and humid seasons and the cold winter on this city. The climate design of the building from the thermal and lighting point of view should be to reduce the effects of the city's inappropriate climate. For this purpose, in order to design residential units from a thermal point, it is necessary to achieve the following objectives. The most basic principles of thermal design of the climate design in this city are:

- Protection against hot outside

- Radiation protection

- Utilize the daily fluctuation of air temperature

- The use of winter heating in the winter

- Reduce thermal waste of the building

- Reduced the effect of dusty winds

- Protects against humidity

- Reduced wind impact in building heat loss in winter

Based on the results obtained, several strategies are presented, along with the image below:

A) Earth sheltering, occupied basements, or earth tubes reduce heat loads in very hot dry climates because the earth stays near average annual temperature (Shape 1).

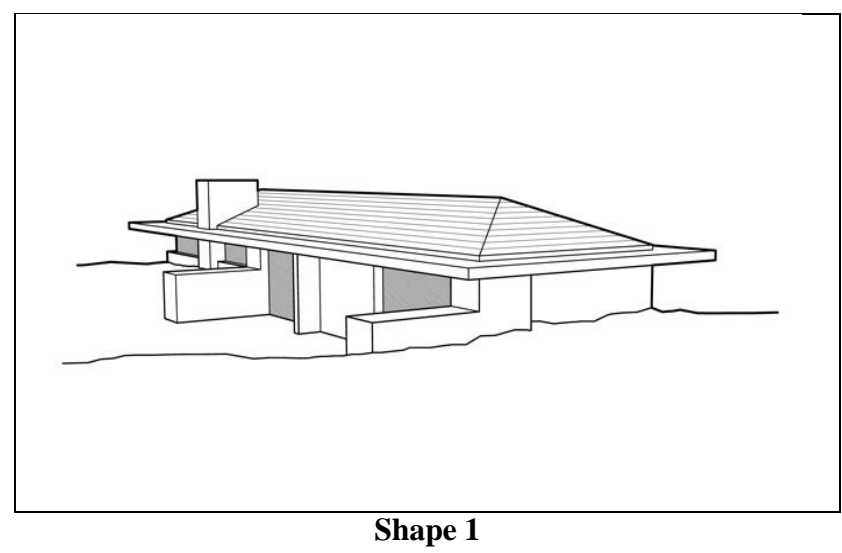

B) Humidify hot dry air before it enters the building from enclosed outdoor spaces with spray-like fountains, misters, wet pavement, or cooling towers (Shape 2). 


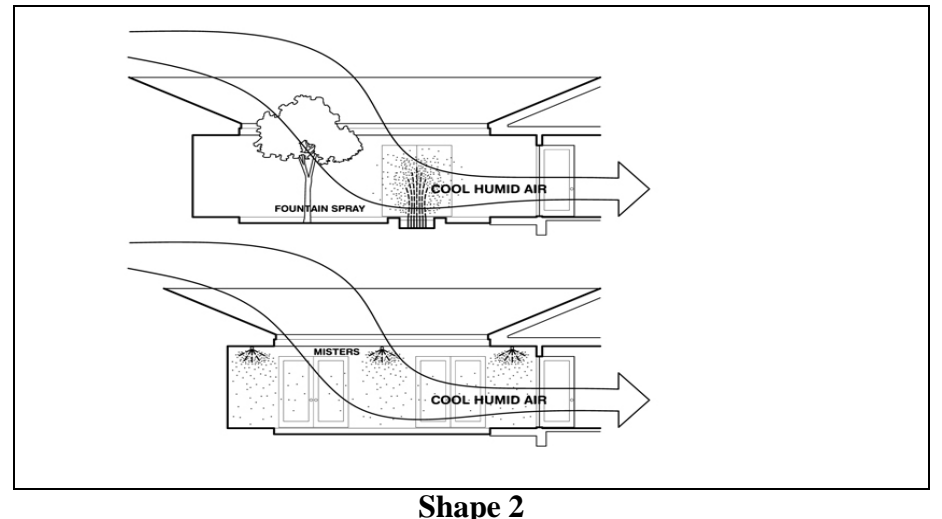

Shape 2

C) Flat roofs work well in hot dry climates (especially if light colored) (Shape 3).

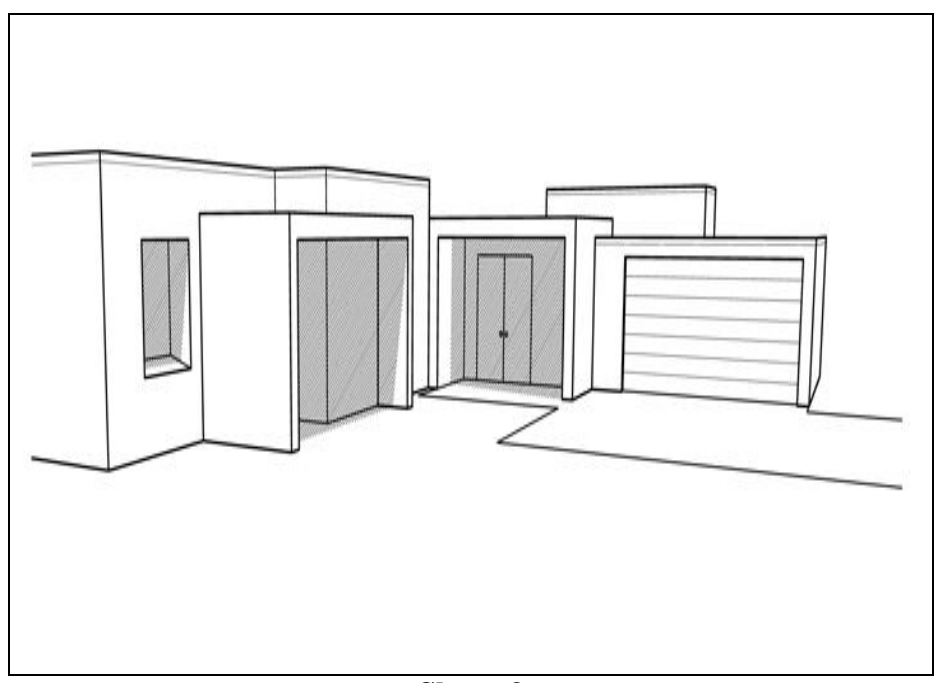

Shape 3

D) On hot days ceiling fans or indoor air motion can make it seem cooler by 5 degrees F (2.8C) or more, thus less air conditioning is needed (Shape 4).

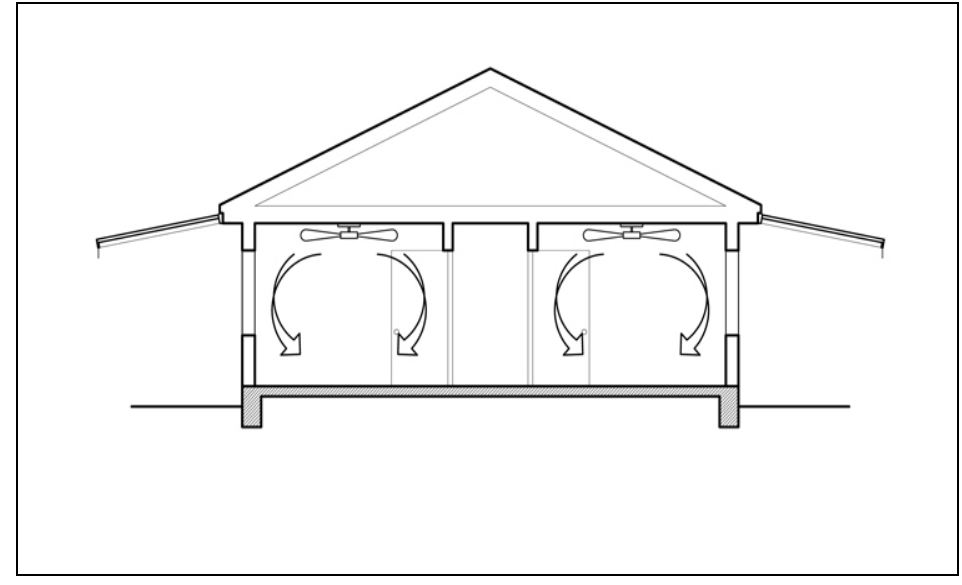

Shape 4

E) Traditional passive homes in hot dry climates used high mass construction with small recessed shaded openings, operable for night ventilation to cool the mass (Shape 5). 


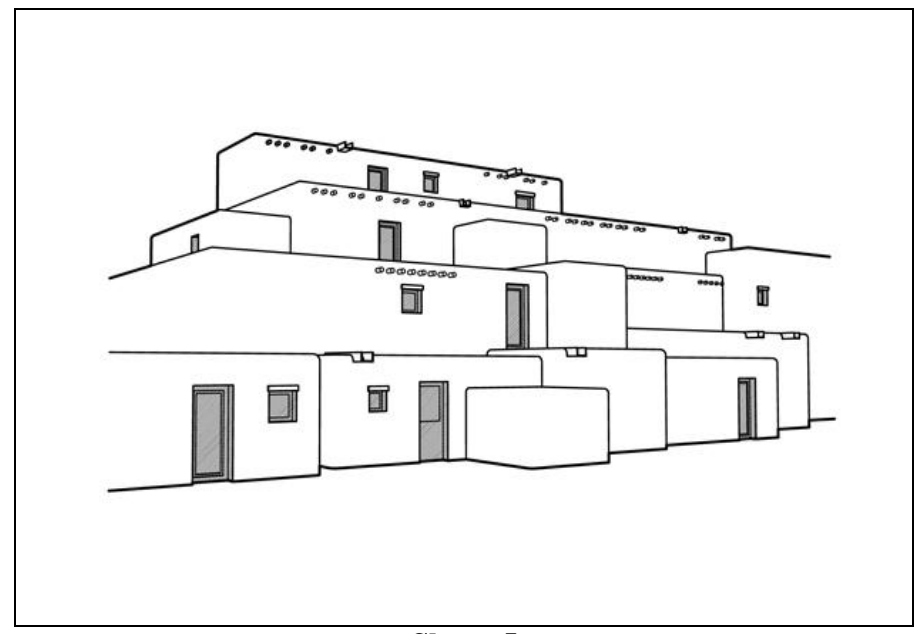

Shape 5

F) Use open plan interiors to promote natural cross ventilation, or use louvered doors, or instead use jump ducts if privacy is required (Shape 6).
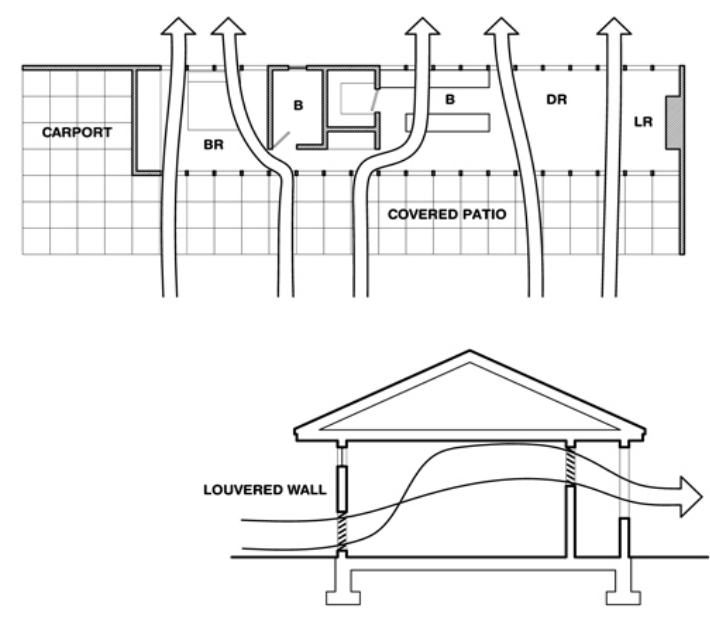

Shape 6

G) Provide enough north glazing to balance daylighting and allow cross ventilation (about 5\% of floor area)

(Shape 7).

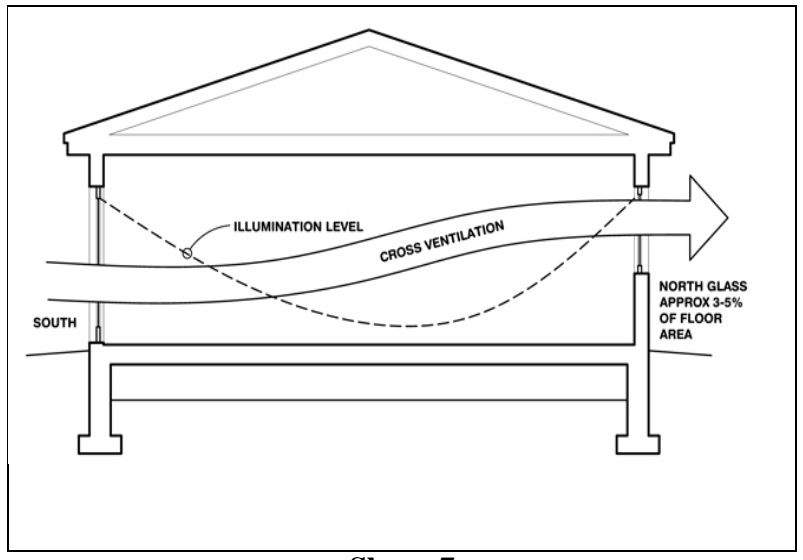

Shape 7

H) Window overhangs (designed for this latitude) or operable sunshades (awnings that extend in summer) can reduce or eliminate air conditioning (Shape 8). 


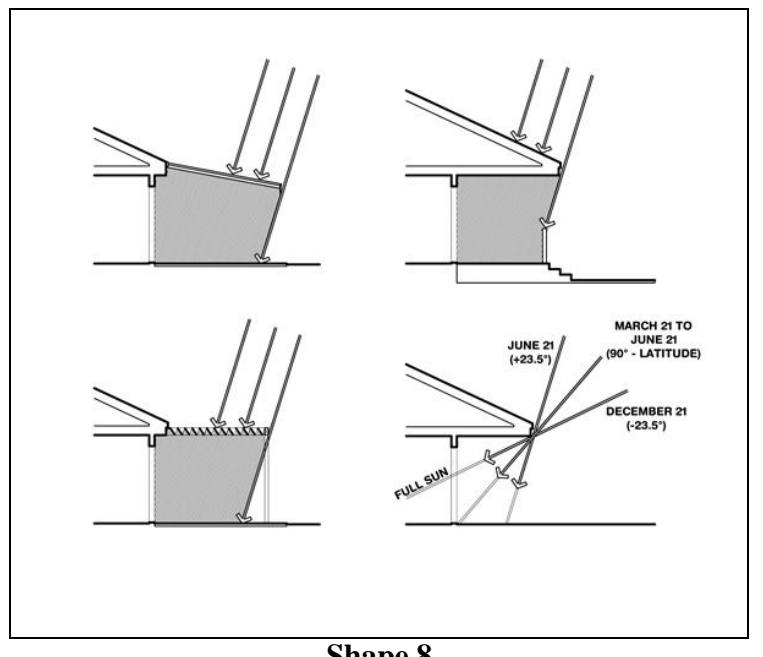

Shape 8

I) Minimize or eliminate west facing glazing to reduce summer and fall afternoon heat gain (Shape 9).

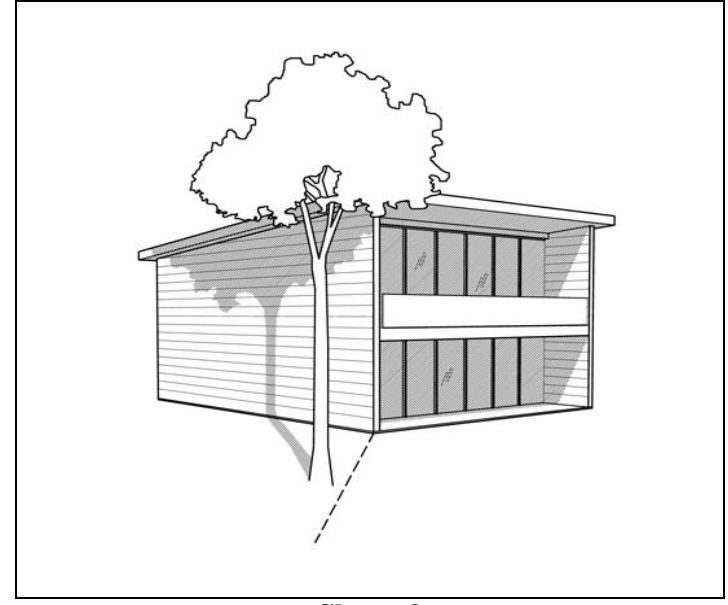

Shape 9

J) Provide double pane high performance glazing (Low-E) on west, north, and east, but clear on south for maximum passive solar gain (Shape 10).

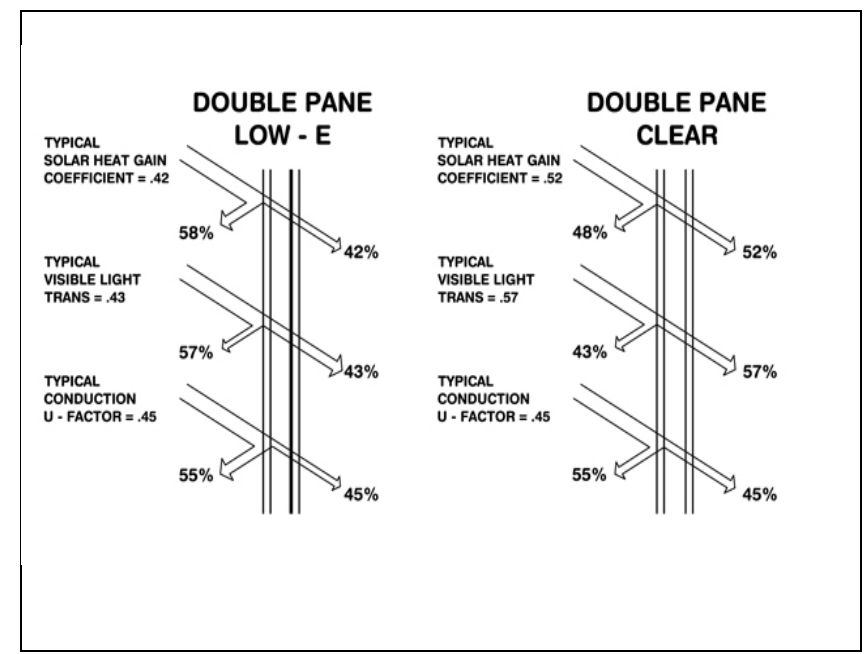

Shape 11 
K) Good natural ventilation can reduce or eliminate air conditioning in warm weather, if windows are well shaded and oriented to prevailing breezes (Shape 11).

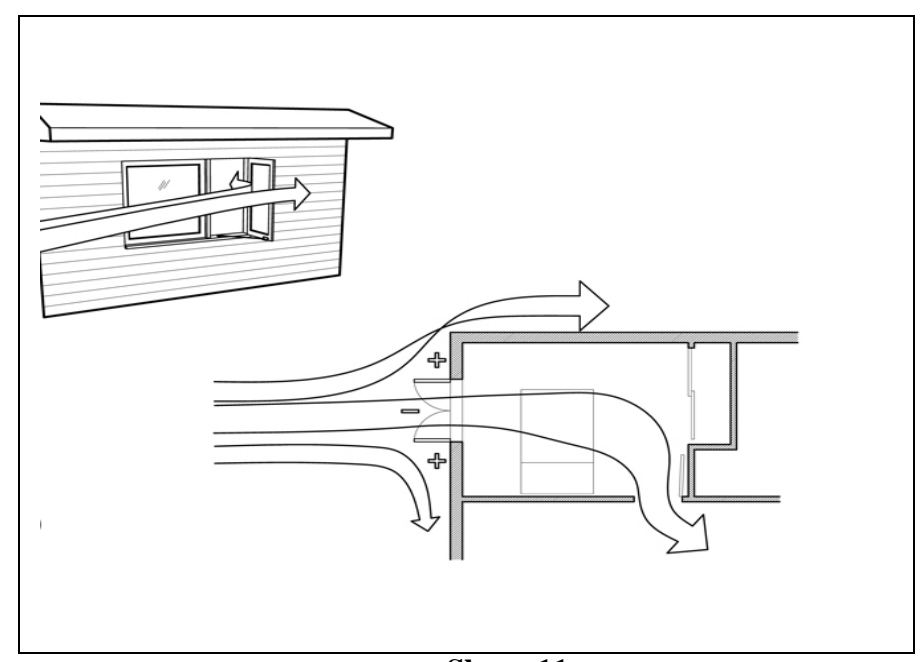

Shape 11

L) Use light colored building materials and cool roofs (with high emissivity) to minimize conducted heat gain (Shape 12).

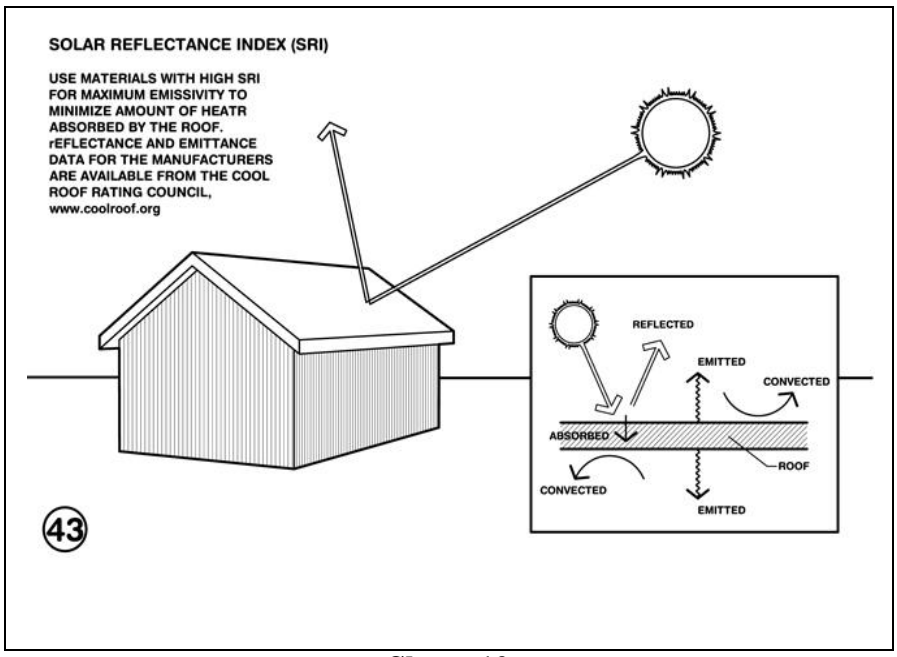

Shape 12

M) To produce stack ventilation, even when wind speeds are low, maximize vertical height between air inlet and outlet (open stairwells, two story spaces, roof monitors) (Shape 13).

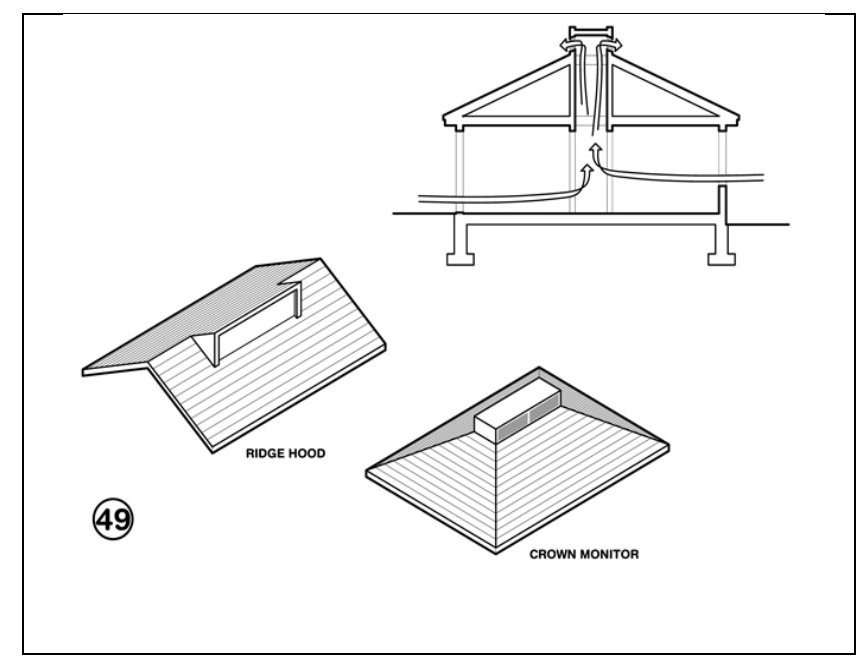

Shape 13 
N) A radiant barrier (shiny foil) will help reduce radiated heat gain through the roof in hot climates (Shape 14).

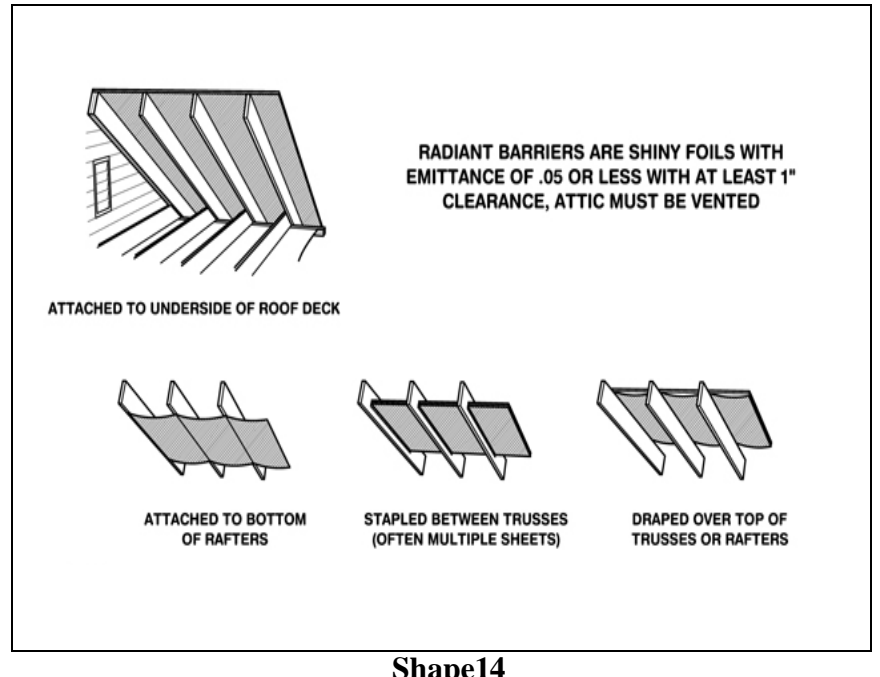

Shape14

O) The best high mass walls use exterior insulation (like EIFS foam) and expose the mass on the interior or add plaster or direct contact drywall (Shape 15).

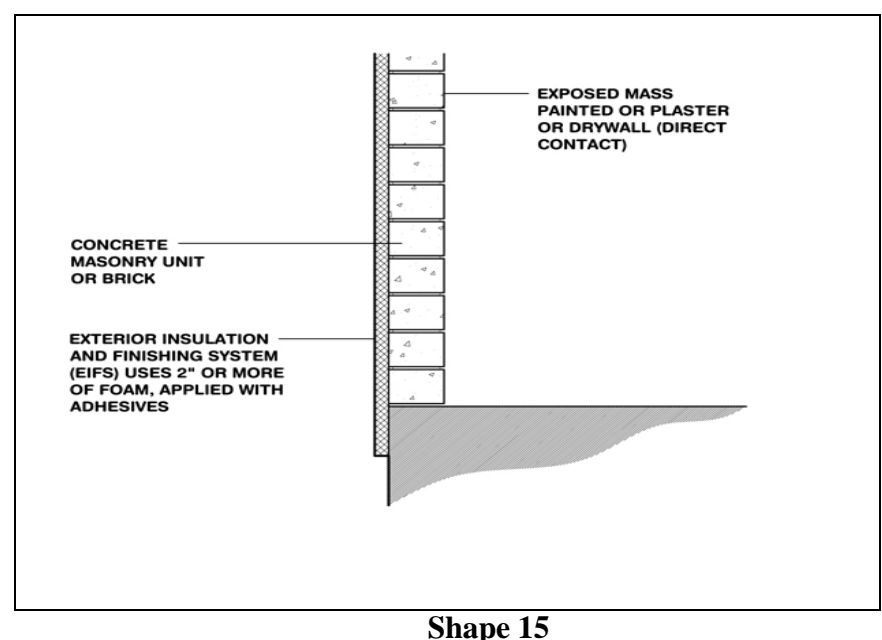

P) For passive solar heating face most of the glass area south to maximize winter sun exposure, but design overhangs to fully shade in summer (Shape 16).

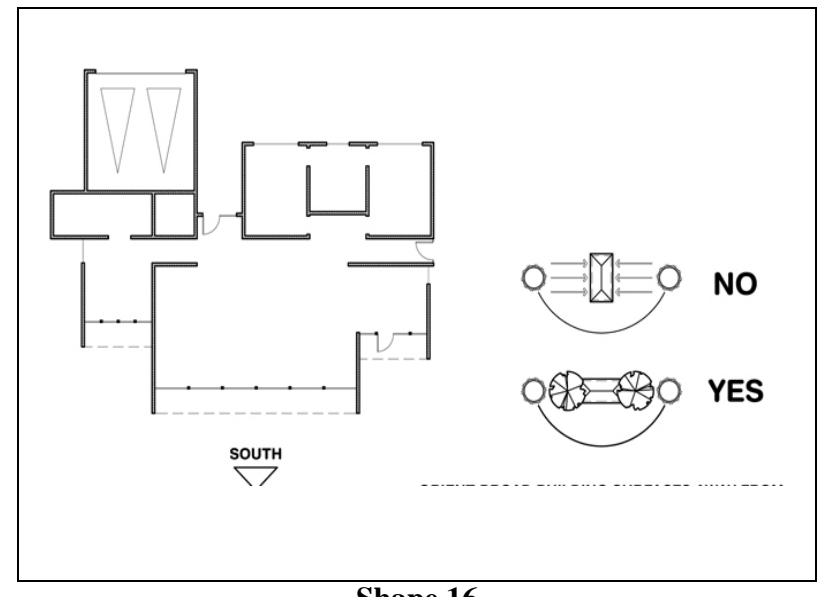

Shape 16 
Q) Raise the indoor comfort thermostat setpoint to reduce air conditioning energy consumption (especially if occupants wear seasonally appropriate clothing) (Shape 17).

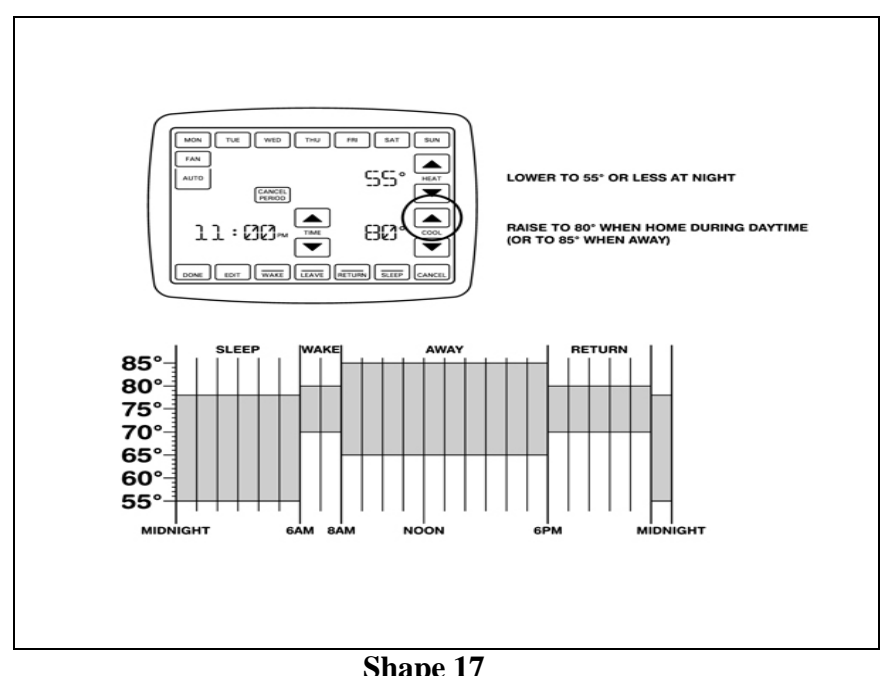

R) Heat gain from lights, people, and equipment greatly reduces heating needs so keep home tight, well insulated (to lower Balance Point temperature) (Shape 18).

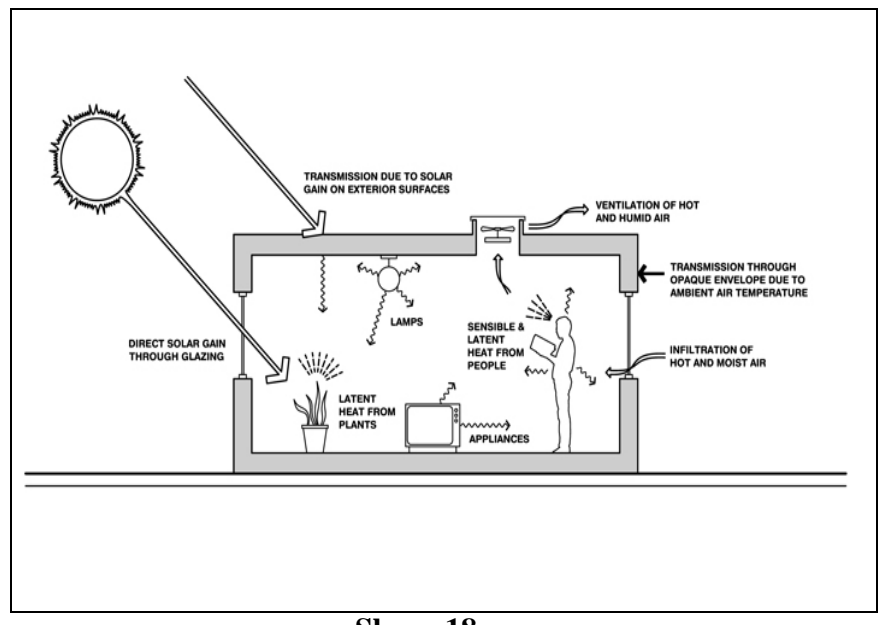

Shape 18

\section{References}

[1] $\mathrm{Xu}, \mathrm{H}$., et al., A quantitative study of the climate-responsive design strategies of ancient timber- frame halls in northern China based on field measurements. Energy and Buildings, 2016.133: p. 306-320. https://doi.org/10.1016/j.enbuild.2016.09.047.

[2] Nguyen, A.-T., et al., An investigation on climate responsive design strategies of vernacular housing in Vietnam. Building and Environment, 2011.46(10): p. 2088-2106. https://doi.org/10.1016/j.buildenv.2011.04.019.

[3] P. Hennicke, S.B, Energierevolution Effizienzsteigerung und erneuerbare Energien als globale Herausforderung. 2010, München: Oekom-Verl.

[4] K.Behbood, Tolou, Mohammad Taleghani, and Shahin Heidari. "Energy Efficient Architectural Design Strategies in Hot-Dry Area of Iran: Kashan." Emirates Journal for Engineering Research Vol.15.2 pp.85-91, 2010.

[5] A. Benardosa, , I. Athanasiadisb, N. Katsoulakosc, Modern earth sheltered constructions: A paradigm of green engineering, Tunnelling and Underground Space Technology, vol. 41, pp 46-52, 2014 . https://doi.org/10.1016/j.tust.2013.11.008.

[6] Tzikopoulos, A.F., M.C. Karatza, and J.A. Paravantis, Modeling energy efficiency of bioclimatic buildings. Energy and Buildings, 2005. 37(5): p. 529-544. https://doi.org/10.1016/j.enbuild.2004.09.002.

[7] Motealleh Parinaz, Z.M., Parsaee Mojtaba, Investigating climate responsive solutions in vernacular architecture of Bushehr city. Housing and Building National Research Center (HBRC), 2016.xxx:p.xxx-xxx.https://doi.org/10.1016/j.hbrcj.2016.08.001.

[8] Tahbaz, M. and S. jalilian, Challenge of Vernacular Architecture and Modern Life Style - Case Study in Iran, in 25th Conference on Passive and Low Energy Architecture. 2008, University College Dublin:Dublin.

[9] Nikghadam, N., Climatic Patterns of Functional Spaces in Vernacular Houses of Bushehr (By Grounded Theory). The Scientific Journal of NAZAR research center (Nrc) for Art, Architecture \& Urbanism, 2015.12(32): p. 77-90(In Persian).

[10] Masoumi, H.R., N. Nejati, and A.a. Ahadi, Learning from the Heritage Architecture: Developing Natural Ventilation in Compact 
Urban Form in Hot-Humid Climate: Case Study of Bushehr, Iran.International Journal of Architectural Heritage, 2017. 11(3): p. 415432. https://doi.org/10.1080/15583058.2016.1238971.

[11] Ranjbar, e., m. pourjafar, and k. khaliji, Innovations In Climatic Designing Due to The Wind Flowing Through The Old Bushehr. The Scientific Journal of NAZAR research center (Nrc) for Art, Architecture \& Urbanism, 2010.7(13): p. 17-34(In Persian).

[12] Mohammadi, A. and S.M.H. Ayatollahi, Designing a model shading device for Bushehr city SOFFEH, 2011.21(3): p. 43-54(In Persian).

[13] Nikghadam, N., The effect of wind and sun on modulating the heating conditions of Bushehr houses Case Study: Golshan House. Iranian Journal of Architecture \& Urbanism, 2016.7(12): p. 29-46(In Persian).

[14] Motealleh, P., M. Zolfaghari, and M. Parsaee, Investigating climate responsive solutions in vernacular architecture of Bushehr city. HBRC Journal, 2016. https://doi.org/10.1016/j.hbrcj.2016.08.001

[15] Shahmortezaei, S.R. and J. Sabernejad, Optimization of Proportions of Central Courtyard based on Comfort Standards in the Traditional Qajar Period Houses in Boushehr. Space Ontology International Journal, 2016.5(2): p. 49-55.

[16] Hazbei, M., Nematollahi, O, Behnia, M, Adib, Z., Reduction of energy consumption using passive architecture in hot and humid climates. Tunnelling and Underground Space Technology, 2015.47(0): p. 16-27. https://doi.org/10.1016/j.tust.2014.12.001.

[17] Safaee, M.M., 2009. SHAVADAN; the sustainable architecture in the city of Dezful in Iran. In: Proceedings of 12th International Conference of the Associated Research Centers for Urban Underground Space (ACUUS2009). 